\title{
Faktor Penentu Pemanfaatan Sertifikat Redistribusi Tanah untuk Mengakses Modal: Studi Kasus Kabupaten Pasaman Barat
}

\author{
Factors that Affect the Use of Land Redistribution Certificates \\ for Accessing Loan: A case study of West Pasaman Regency
}

\author{
Monsaputra $^{1^{*}}$, Khursatul Munibah $^{1,2}$ \& Dyah Retno Panuju ${ }^{2,3}$
}

\begin{abstract}
${ }^{1}$ Program Studi Ilmu Perencanaan Wilayah, Fakultas Pertanian, Institut Pertanian Bogor, Indonesia; ${ }^{2}$ Departemen Ilmu Tanah dan Sumberdaya Lahan, Fakultas Pertanian, Institut Pertanian Bogor, Jalan Meranti, Kampus IPB Dramaga Bogor, Jawa Barat, 16680, Indonesia; ${ }^{3}$ Pusat Pengkajian Perencanaan dan Pengembangan Wilayah, Institut Pertanian Bogor, Kampus IPB Baranang Siang, Bogor, 16127, Indonesia;

*Penulis korespondensi.e-mail: mon_eps40@yahoo.com

(Diterima: 26 April 2021; Disetujui: 23 Agustus 2021)
\end{abstract}

\begin{abstract}
West Pasaman Regency has implemented land redistribution to rearrange land tenure, land ownership, land use, and utilization of land. Land redistribution certificates can be used as collateral. The number of redistribution certificates in 2009 until 2018 complemented with mortgage rights was 871 (7,79\%). This study aims to determine the factors that affect the use of certificates as collateral for accessing loan. The methods of analysis used was quantitative with surveys and data analysis technique used was logistic regression. The logistic regression resulted several significant factors influencing the use of certificates for collateral including the number of family members, expenditures and land area. Household expenditure and land area had a positive influence, meanwhile the number of family members had a negative effect. Household welfare is an essential factor affecting the likelihood for collateral of land certificates.
\end{abstract}

Keywords: acces reform, agrarian reform

\begin{abstract}
ABSTRAK
Kabupaten Pasaman Barat telah mengimplementasikan program redistribusi tanah untuk menata kembali penguasaan, pemilikan, penggunaan, dan pemanfaatan tanah. Sertifikat redistribusi tanah dapat digunakan sebagai agunan. Selama tahun 2009 hingga 2018 sertifikat redistribusi tanah yang diagunkan sebanyak 871 buah $(7.79 \%)$. Penelitian ini bertujuan untuk menganalisis faktor yang memengaruhi pemanfaatan sertifikat redistribusi tanah sebagai agunan untuk mengakses modal. Metode penelitian yang digunakan adalah metode kuantitatif dengan survei dan teknik analisis data yang digunakan adalah regresi logistik. Faktor yang signifikan memengaruhi pemanfaatan sertifikat sebagai agunan untuk mengakses modal adalah jumlah anggota keluarga, luas, dan pengeluaran. Variabel pengeluaran dan luas memiliki hubungan positif, sedangkan jumlah anggota keluarga memiliki hubungan negatif. Kesejahteraan penerima sertifikat merupakan faktor penting yang berpengaruh pada pemanfaatan sertifikat untuk agunan.
\end{abstract}

Kata kunci: reforma agraria, reforma akses 


\section{PENDAHULUAN}

Reforma agraria (land reform) merupakan program pemerintah untuk menata kembali penguasaan, pemilikan, penggunaan dan pemanfaatan tanah yang berkeadilan melalui pembagian atau redistribusi tanah kepada masyarakat dengan syarat-syarat tertentu. Kegiatan redistribusi tanah dilaksanakan di berbagai negara dan secara umum bertujuan untuk memperbaiki keadaan sosial ekonomi masyarakat dengan membagi tanah pertanian secara adil sekaligus memberikan kepastian hak atas tanah (Mendola \& Simtowe, 2015; Mukarati et al., 2020). Di Indonesia, kegiatan tersebut merupakan wujud pelaksanaan Undang Undang Dasar 1945 Pasal 33, Undang Undang Pokok Agraria (UUPA) serta TAP MPR nomor IX/MPR/2001 tentang Pembaruan Agraria dan Pengelolaan Sumberdaya Alam (Fatimah, 2015).

Di semua negara, tanah objek reforma agraria ditentukan dan diatur melalui kebijakan pemerintah yang dipayungi dengan peraturan perundangan. Tanah objek land reform di Indonesia sebagaimana diatur dalam Peraturan Pemerintah Nomor 224 Tahun 1961, berasal dari tanah kelebihan maksimum, tanah absentee, tanah swapraja dan bekas swapraja serta tanah negara lainnya yang dikuasai oleh negara dan ditetapkan oleh pemerintah sebagai objek reforma agraria. Setelah dibagikan, tanah tersebut tidak dapat dialihkan haknya baik sebagian atau seluruhnya dalam jangka waktu 10 tahun, kecuali kepada pihak yang memenuhi persyaratan dengan persetujuan tertulis dari Kepala Kantor Pertanahan (Isnaeni, 2017b).

Redistribusi tanah sendiri merupakan bagian dari program reforma agraria untuk meningkatkan kesejahteraan masyarakat miskin melalui skema asset reform dan access reform (Waryanta, 2016). Asset reform dilakukan dengan memberikan tanah kepada masyarakat yang memerlukan, sedangkan access reform adalah memberikan akses kepada penerima asset reform agar mampu memberdayakan tanahnya untuk meningkatkan kesejahteraan melalui penyediaan infrastruktur, pembiayaan, pengolahan, pasca produksi, hingga distribusinya (Fatimah, 2015; Arisaputra, 2016). Wiradi (2000) menyatakan kegiatan reforma agraria yang hanya berupa redistribusi tanah kurang berhasil meningkatkan kesejahteraan karena buruh tani penerima tanah tidak mampu mengusahakan sendiri tanah tersebut karena kekurangan modal, kurang keterampilan atau alasan lainnya sehingga akhirnya tanahnya dijual. Lebih rinci menurut Isnaeni (2017b) di samping pemberian tanda bukti hak atas tanah, kegiatan redistribusi lahan perlu dilanjutkan dengan memberikan fasilitas terhadap modal, teknologi, pasar, peningkatan kapasitas, manajemen dan pendampingan. Upaya lanjutan ini dibutuhkan agar tanah yang diperoleh dapat dimanfaatkan dengan optimal dan berdampak pada meningkatnya taraf hidup penerima sertifikat.

Beberapa penelitian lain menunjukkan bahwa kegiatan redistribusi tanah dapat meningkatkan kesejahteraan masyarakat. Sebagai contoh adalah kegiatan redistribusi tanah di Kulon Bambang, Desa Sumber Urip, Kecamatan Doko, Kabupaten Blitar (Isnaeni, 2017a) dan kegiatan redistribusi tanah di Desa Mendiro, Kecamatan Ngrambe, Kabupaten Ngawi, Provinsi Jawa Timur (Soetarto et al., 2007). Pada studi kasus di Filipina, kegiatan redistribusi tanah yang disertai penyediaan kredit dilaporkan juga berhasil menurunkan kemiskinan petani (Das, 2008). Pemikiran Wiradi (2000) maupun hasil studi di Blitar (Isnaeni, 2017a), Ngawi (Soetarto et al., 2007) serta di Filipina (Das, 2008) menunjukkan bahwa kegiatan redistribusi tanah di berbagai wilayah cenderung memberikan hasil yang berbeda terhadap petani atau subjek penerimanya. Dengan demikian penelitian di wilayah lain perlu dilakukan untuk menguji ulang dan memahami fenomena kegiatan redistribusi tanah.

Penelitian lanjutan terkait kegiatan redistribusi tanah umumnya mengidentifikasi pemanfaatan sertifikat untuk mengakses modal. Modal adalah salah satu faktor yang memengaruhi usaha tani (Supanggih \& Widodo, 2013). Tidak semua masyarakat dapat 
menerima pembiayaan lembaga keuangan karena tidak mempunyai agunan (Jubaya \& Wulandari, 2015). Beberapa penelitian menunjukkan bahwa sertifikat tanah digunakan oleh penerima program reforma agraria sebagai alat untuk mengakses modal usaha, seperti penelitian Purnamasari \& Hutagalung (2012) di Kecamatan Tanjung Bintang, Kabupaten Lampung Selatan serta Sugiyanto et al. (2008) di Kabupaten Ngawi. Namun demikian, berbagai penelitian tersebut tidak secara spesifik mengidentifikasi faktor yang terkait erat dengan penggunaan sertifikat redistribusi tanah untuk mengakses modal. Kajian identifikasi faktor tersebut perlu dilakukan untuk mengetahui secara rinci alasan dan karakteristik penerima objek tanah yang terkait dengan pemanfaatan sertifikat redistribusi tanah untuk mengakses modal usaha.

Untuk mengidentifikasi dan menganalisis berbagai variabel yang diduga berperan dalam menentukan keputusan penggunaan sertifikat untuk mengakses modal dipilih lokasi yang telah menerapkan kegiatan redistribusi tanah, yaitu Kabupaten Pasaman Barat. Berdasarkan data Kantor Pertanahan Kabupaten Pasaman Barat (2009 sampai 2018), telah dilaksanakan kegiatan redistribusi tanah sebanyak 11,140 bidang yang tersebar di tujuh kecamatan. Kecamatan Ranah Batahan adalah lokasi dengan subjek penerima terbanyak yaitu 4,513 bidang, dengan jumlah redistribusi tertinggi pada tahun 2010 yaitu sebanyak 2,650 bidang yang tersebar di empat nagari dan jumlah objek diredistribusikan menurun setelahnya.

Sasaran kegiatan redistribusi tanah di Kabupaten Pasaman Barat mayoritas adalah kebun kelapa sawit (BPN, 2020). Tambahan modal dapat meningkatkan kualitas pemeliharaan tanaman sehingga kualitas buah sawit yang dihasilkan lebih baik dan petani memperoleh harga jual yang lebih tinggi. Modal dari kegiatan access reform juga dapat digunakan untuk memulai penanaman atau peremajaan kebun sawit, memperoleh bibit berkualitas sehingga kualitas output maksimal.
Harga jual yang lebih baik akan dapat meningkatkan kesejahteraan petani.

Berdasarkan uraian di atas, artikel ini bertujuan untuk mengidentifikasi faktor penentu yang terkait erat dengan keputusan penerima redistribusi tanah dalam menggunakan sertifikatnya untuk mengakses modal.

\section{METODOLOGI}

Penelitian ini menggunakan metode survei untuk pengumpulan data primer yaitu dengan menyebarkan kuesioner dan wawancara dengan menggunakan daftar pertanyaan terstruktur terhadap responden terpilih serta data sekunder baik berupa tabel maupun peta dari Badan Pertanahan Nasional dan Badan Pusat Statistik Kabupaten Pasaman Barat.

Kuesioner dan wawancara digunakan untuk memperoleh informasi berbagai karakteristik responden dan faktor-faktor yang dihipotesiskan relevan dengan pemanfaatan sertifikat sebagai agunan untuk mengakses modal. Di samping itu kuesioner juga digunakan untuk menggali informasi terkait perubahan tingkat kesejahteraan masyarakat sebelum dan setelah memiliki sertifikat hasil redistribusi tanah. Jumlah sampel responden ditentukan menggunakan rumus Slovin, sebagai berikut:

dimana:

$$
n=\frac{N}{\left(1+N e^{2}\right)}
$$

$\mathrm{n}=$ jumlah sampel

$\mathrm{N}=$ jumlah sertifikat redistribusi

$\mathrm{e}=$ ketelitian atau tingkat akurasi $(10 \%=0.1)$.

Pengambilan sampel dilakukan secara berstrata (stratified sampling) berdasarkan informasi dasar antara lain jumlah penerima redistribusi tanah per wilayah kecamatan, jarak lahan ke tanah, luas tanah dan Zona Nilai Tanah (ZNT). Pengambilan sampel secara berstrata ini diharapkan menghasilkan data yang mewakili keragaman informasi dasar tersebut.

Proses pengambilan sampel diawali dengan membagi kelas penerima sertifikat redistribusi tanah menjadi yang sudah 
menggunakan sertifikat sebagai agunan dan yang belum menggunakan sertifikat sebagai agunan. Sertifikat redistribusi tanah yang sudah diagunkan sebanyak 871 bidang dan yang belum digunakan untuk agunan sebanyak 10,269 bidang (BPN, 2020). Secara proporsional jumlah sampel (responden) sertifikat redistribusi tanah yang belum diagunkan sebanyak:

$$
\begin{gathered}
n=\frac{10,269}{\left(1+10,269 \times 0.1^{2}\right)} \\
n=99.03 \sim 100
\end{gathered}
$$

Sedangkan jumlah sampel sertifikat redistribusi tanah yang sudah diagunkan sebanyak:

$$
\begin{gathered}
n=\frac{871}{\left(1+871 \times 0.1^{2}\right)} \\
n=89.7 \sim 90
\end{gathered}
$$

Selanjutnya, diambil jumlah contoh secara proporsional untuk setiap kelompok berdasarkan nilai tanah, jarak dari jalan dan luas tanah. Untuk melihat faktor yang memengaruhi pemanfaatan sertifikat sebagai agunan untuk mengakses modal digunakan regresi logistik. Persamaan umum regresi logistik adalah sebagai berikut:

$$
\begin{array}{ll} 
& \ln \left(\frac{\hat{p}}{1-\hat{p}}\right)=B_{0}+B_{1} X \\
\hat{p} & : \text { probabilitas logistik } \\
\mathrm{B}_{\mathrm{o}} & : \text { konstanta } \\
\mathrm{B}_{1} & : \text { koefisien regresi } \\
\mathrm{X} & : \text { variabel bebas }
\end{array}
$$

Variabel tak bebas dalam analisis regresi logistik ini adalah status mengagunkan sertifikat,

\begin{tabular}{|c|c|c|c|}
\hline No. & Jenis Variabel & $\begin{array}{l}\text { Tipe } \\
\text { Data }\end{array}$ & Keterangan \\
\hline 1 & Umur & numerik & - \\
\hline 2 & $\begin{array}{l}\text { Tingkat } \\
\text { pendidikan }\end{array}$ & numerik & - \\
\hline 3 & $\begin{array}{l}\text { Pemahaman } \\
\text { pemanfaatan } \\
\text { sertifikat } \\
\text { sebagai agunan }\end{array}$ & kategori & $\begin{array}{r}0: \text { tidak } \\
\text { paham } \\
1: \text { kurang } \\
\text { paham } \\
2: \text { paham }\end{array}$ \\
\hline 4 & $\begin{array}{l}\text { Jumlah anggota } \\
\text { keluarga }\end{array}$ & numerik & - \\
\hline 5 & $\begin{array}{l}\text { Kepemilikan } \\
\text { kredit } \\
\text { sebelumnya }\end{array}$ & kategori & $\begin{array}{r}1: \text { belum } \\
\text { punya } \\
\text { kredit } \\
0: \text { sudah } \\
\text { punya } \\
\text { kredit }\end{array}$ \\
\hline 6 & $\begin{array}{l}\text { Luas } \\
\text { kepemilikan } \\
\text { tanah }\end{array}$ & numerik & - \\
\hline 7 & $\begin{array}{l}\text { Pengeluaran per } \\
\text { bulan }\end{array}$ & numerik & - \\
\hline 8 & Nilai tanah & numerik & - \\
\hline 9 & Jarak dari jalan & numerik & - \\
\hline
\end{tabular}
yaitu bernilai 1 jika mengagunkan dan bernilai 0 jika belum mengagunkan. Sembilan buah variabel bebas dipilih sebagai faktor yang dihipotesiskan memengaruhi pemanfaatan sertifikat redistribusi tanah untuk agunan dan diuji pengaruhnya. Variabel bebas tersebut disajikan pada Tabel 1.
Tabel 1. Jenis dan tipe data variabel bebas

Tes Hosmer and Lemeshow dilakukan untuk menentukan ketepatan model yang dibentuk. Pengujian didasarkan pada sebaran Khi-kuadrat (Chi-square). Model dinyatakan tepat jika perbedaan antara prediksi model dengan nilai observasi sangat kecil atau tidak nyata. Pengujian hipotesis dengan konsep Hosmer and Lemeshow adalah sebagai berikut (Fagerland \& Hosmer, 2012; Khaeri \& Pawitan 2018):

$\mathrm{H}_{0}$ : model cukup mampu menjelaskan data.

$\mathrm{H}_{1}$ : model tidak cukup mampu menjelaskan data.

Selanjutnya dilakukan uji parsial untuk menilai variabel independen yang berpengaruh nyata dilihat dari nilai uji dengan derajat kesalahan (p-value) yang ditetapkan yaitu 0.05 atau tingkat ketepatan 95\%. Besarnya pengaruh variabel bebas ditunjukkan oleh nilai rasio odd yang merupakan eksponen dari koefisien regresi. 
Semakin tinggi nilai rasio odd, maka semakin besar pengaruh sebuah variabel bebas terhadap keputusan mengagunkan atau tidaknya sertifikat tanah untuk mengakses modal.

\section{HASIL DAN PEMBAHASAN}

Dari hasil wawancara dan penggalian informasi diketahui bahwa dalam proses mengakses modal usaha, sertifikat hak tanggungan akan diterbitkan untuk setiap hak kepemilikan sebagai bukti hukum objek tersebut sedang diagunkan. Data ini tercatat di Kantor Pertanahan setempat. Berdasarkan data dari Kantor Pertanahan Kabupaten Pasaman Barat, jumlah sertifikat redistribusi tanah tahun 2009 sampai 2018 yang sudah memiliki hak tanggungan sebanyak 871 bidang (7.79\%). Tabel 2 memperlihatkan sebaran data responden.

Secara umum Tabel 2 menunjukkan bahwa penerima redistribusi tanah berusia antara 23 tahun sampai 75 tahun, dengan tingkat pendidikan paling tidak lulus sekolah dasar, sampai dengan lulus sekolah menengah atas. Rerata responden memiliki anggota keluarga 4 orang, dan belum pernah mengakses kredit sebelumnya. Total luas tanah yang dimiliki berkisar antara 0.8 ha sampai dengan 2.6 ha dan objek redistribusi berlokasi antara $0.5 \mathrm{~km}$ hingga $4 \mathrm{~km}$ dari jalan.

Tabel 2. Sebaran data responden

\begin{tabular}{|c|c|c|c|c|c|}
\hline \multirow[t]{2}{*}{ No. } & \multirow[t]{2}{*}{ Variabel } & \multicolumn{3}{|c|}{ Data responden } & \multirow[t]{2}{*}{ Keterangan } \\
\hline & & Minimum & Maksimum & Median & \\
\hline 1 & Umur & 23 & 75 & 47 & - \\
\hline 2 & $\begin{array}{l}\text { Tingkat } \\
\text { pendidikan }\end{array}$ & 6 & 16 & 12 & - \\
\hline 3 & $\begin{array}{l}\text { Pemahaman } \\
\text { pemanfaatan }\end{array}$ & - & - & - & $\begin{array}{ll}\text { paham } & : 155 \\
\text { kurang paham }: & 32\end{array}$ \\
\hline & $\begin{array}{l}\text { sertifikat sebagai } \\
\text { agunan }\end{array}$ & & & & tidak paham : 3 \\
\hline 4 & $\begin{array}{l}\text { Jumlah anggota } \\
\text { keluarga }\end{array}$ & 1 & 8 & 4 & - \\
\hline 5 & $\begin{array}{l}\text { Kepemilikan } \\
\text { kredit } \\
\text { sebelumnya }\end{array}$ & - & - & - & $\begin{array}{l}\text { belum : } 146 \\
\text { sudah : } 44\end{array}$ \\
\hline 6 & $\begin{array}{l}\text { Luas } \\
\text { kepemilikan } \\
\text { tanah }\left(\mathrm{m}^{2}\right)\end{array}$ & 8,024 & 26,316 & 10,500 & - \\
\hline 7 & $\begin{array}{l}\text { Pengeluaran per } \\
\text { bulan }(\mathrm{Rp})\end{array}$ & $1,000,000.00$ & $5,500,000.00$ & $2,000,000.00$ & - \\
\hline 8 & $\begin{array}{l}\text { Nilai tanah (000 } \\
\text { Rp) }\end{array}$ & 1,000 & 7,000 & 6,000 & - \\
\hline 9 & $\begin{array}{l}\text { Jarak dari jalan } \\
\text { (m) }\end{array}$ & 500 & 4,000 & 1,000 & - \\
\hline
\end{tabular}

Tabel 3 memperlihatkan hasil uji parsial variabel yang dihipotesiskan berpengaruh terhadap keputusan mengakses modal usaha dengan memanfaatkan sertifikat tanah. Secara umum terdapat dua kelompok peran pengaruh berbagai variabel bebas yang dihipotesiskan, yaitu berperan meningkatkan peluang mengagunkan (koefisien positif) dan menurunkan peluang untuk mengagunkan tanah (koefisien negatif). Faktor yang signifikan 
$(\alpha=5 \%)$ memengaruhi pemanfaatan sertifikat sebagai agunan untuk akses modal adalah jumlah anggota keluarga, luas tanah dan pengeluaran rumah tangga. Jumlah anggota keluarga berpengaruh negatif terhadap peluang mengagunkan sertifikat sedangkan luas tanah serta jumlah pengeluaran rata-rata per bulan berperan meningkatkan peluang mengagunkan sertifikat tanah untuk mengakses modal.

Tabel 3. Hasil uji signifikansi parsial

\begin{tabular}{lccc}
\hline & $\mathrm{B}$ & $\mathrm{p}$ & $\mathrm{Exp}(\mathrm{B})$ \\
\hline Intersep & -3.561 & 0.134 & 0.028 \\
Usia (X1) & 0.017 & 0.552 & 1.017 \\
Pendidikan (X2) & 0.032 & 0.755 & 0.969 \\
Pemahaman pemanfaatan sertifikat sebagai & 210394 & 0.997 & 1955944746 \\
agunan X3) & & & \\
Jumlah anggota keluarga (X4) & -0.385 & 0.039 & 0.680 \\
Kredit (X5) & -0.450 & 0.439 & 0.638 \\
Luas (X6) & 2.818 & 0.000 & 16.747 \\
Pengeluaran (X7) & 0.483 & 0.042 & 1.620 \\
ZNT (X8) & -0.087 & 0.578 & 0.917 \\
Jarak (X9) & 0.044 & 0.870 & 1.045 \\
\hline
\end{tabular}

Uji Hosmer-Lemeshow $, \chi^{2}=1.878, \mathrm{df}=8, \mathrm{p}=0.985$

Berdasarkan hasil uji Hosmer-Lemeshow, diketahui bahwa model cukup baik merepresentasikan data. Tabel 3 memperlihatkan nilai Khi-kuadrat sebesar 1,878, lebih kecil dari nilai Khi-Kuadrat tabel sehingga terima $\mathrm{H}_{0}$. Tabel 4 memperlihatkan hasil ketepatan klasifikasi, nilai proporsi prediksi yang tepat adalah sebesar $(83+79) / 190=$ 85.3\%. Angka ini tergolong cukup baik mengingat tingkat kesalahannya kurang dari $15 \%$.

Tabel 4. Hasil ketepatan klasifikasi

\begin{tabular}{lrr}
\hline & Diagunkan & \multicolumn{1}{c}{$\begin{array}{c}\text { Belum } \\
\text { diagunkan }\end{array}$} \\
\hline Diagunkan & 83 & 7 \\
Belum diagunkan & 21 & 79 \\
\hline & Akurasi & $85.3 \%$ \\
\hline
\end{tabular}

Pengaruh variabel secara parsial terhadap peluang mengakses modal dapat dilihat dari nilai rasio odds $(\operatorname{Exp}(B))$. Variabel jumlah anggota keluarga memiliki nilai odds rasio sebesar 0.679. Angka ini menunjukkan bahwa penerima sertifikat redistribusi tanah yang memiliki jumlah anggota keluarga lebih banyak memiliki peluang untuk mengagunkan 0.679 kali lebih besar dibandingkan yang memiliki jumlah anggota keluarga sedikit. Ini berarti bahwa penerima sertifikat redistribusi tanah yang memiliki lebih sedikit anggota keluarga berpeluang lebih besar untuk mengagunkan sertifikatnya. Hasil ini sejalan dengan penelitian Wati (2015) yang menyatakan jumlah anggota keluarga berhubungan negatif dengan keputusan dalam mengakses kredit. Hal ini dapat berdampak pada terhambatnya peningkatan kesejahteraan karena petani yang memiliki jumlah anggota keluarga lebih banyak akan mengalami kesulitan dalam peningkatan aktivitas perekonomian.

Berdasarkan nilai rasio odds diketahui bahwa peningkatan luas tanah per hektar meningkatkan peluang untuk mengagunkan 
16.71 kali lebih besar. Hal ini menunjukkan bahwa yang memiliki tanah lebih luas berpeluang lebih besar mengagunkan tanah dibandingkan dengan yang memiliki luas tanah lebih kecil. Ini berarti penerima sertifikat redistribusi tanah yang memiliki tanah yang luas lebih berpeluang untuk mengagunkan. Ini sejalan dengan hasil penelitian Wati et al. (2018) bahwa lahan garapan yang lebih luas akan meningkatkan peluang untuk mengakses kredit. Dalam penelitian lain di Afrika Selatan, diketahui bahwa luas tanah yang diredistribusikan merupakan faktor penting yang berpengaruh pada preferensi petani untuk berpartisipasi dalam program redistribusi tanah (Zantsi, 2019). Dengan demikian, dapat dinyatakan bahwa pemilihan variabel luas tanah sebagai salah satu variabel penentu peluang mengagunkan relatif tepat. Hal ini memperlihatkan bahwa yang memiliki tanah lebih luas berpeluang untuk meningkatkan kesejahteraan sedangkan yang memiliki tanah lebih kecil cenderung akan berada pada tingkat kehidupan yang relatif tidak berubah.

Besarnya pengeluaran rumah tangga merupakan penduga tingkat kesejahteraan yang umum digunakan (Rianto, 2011; Nurohman et al., 2019). Nilai rasio-odds menunjukkan bahwa peningkatan satu satuan pengeluaran rumah tangga meningkatkan peluang untuk mengagunkan 1.615 kali lebih besar. Ini berarti penerima sertifikat redistribusi tanah yang memiliki pengeluaran yang tinggi berpeluang lebih besar untuk mengagunkan. Hal ini sejalan dengan hasil penelitian Sartika \& Karyani (2018) yang menyatakan petani dengan jumlah pendapatan yang lebih tinggi memiliki kesempatan mendapatkan akses kredit dari lembaga keuangan bank. Pendapatan yang lebih tinggi diasumsikan berbanding lurus dengan peningkatan pengeluaran.

Hasil uji pengaruh variabel secara parsial memperlihatkan bahwa peluang mengagunkan lebih besar pada penerima sertifikat yang memiliki pengeluaran per kapita yang lebih tinggi. Berdasarkan hasil wawancara, sebagian masyarakat yang memiliki tingkat pengeluaran per kapita lebih rendah diketahui alasannya belum memanfaatkan sertifikat untuk agunan karena belum memiliki kepercayaan diri untuk memanfaatkan modal yang diperoleh. Kepercayaan diri ini berhubungan dengan kekhawatiran tidak dapat membayar pinjaman dan ketidakpastian bahwa modal yang didapat bisa digunakan untuk aktivitas produktif dan menghasilkan pendapatan lebih tinggi. Hal ini harus menjadi perhatian instansi pemerintah untuk memberdayakan petani dengan pendapatan rendah agar lebih terdorong untuk mengagunkan sertifikat guna mengakses modal usaha. Petani miskin dengan pendapatan kecil pada dasarnya merupakan target utama penerima program redistribusi tanah dan seharusnya memperoleh berbagai fasilitas (bantuan) yang dibutuhkan khususnya terkait pengusahaan tanah redistribusi. Pendampingan dari instansi terkait sangat diperlukan supaya masyarakat miskin penerima redistribusi tanah bisa mengakses kredit dan memiliki kepercayaan diri dalam memanfaatkan modal yang diperoleh. Pemanfaatan access reform oleh petani miskin dengan pendapatan kecil akan menjadi instrumen untuk meningkatkan kesejahteraan.

Penerima sertifikat redistribusi tanah yang belum mengagunkan sertifikat memiliki beberapa alasan, yaitu:

1. Penerima sertifikat belum membutuhkan tambahan modal atau belum ada rencana pemanfaatan modal. Hal ini bisa jadi berkaitan dengan kurangnya wawasan terkait peluang-peluang untuk memanfaatkan modal usaha, guna meningkatkan pendapatan dari hasil usaha yang dilakukan, baik terkait usaha tani maupun usaha lain di bidang nonpertanian. Hal ini terjadi pada berbagai skala luas kepemilikan lahan. Faktor yang lebih dominan memengaruhi adalah pemahaman dari individu masing-masing penerima redistribusi tanah dibandingkan dengan strategi livelihood mereka. Kurangnya wawasan ini bisa dijembatani melalui pendampingan yang bisa membuka pandangan masyarakat tentang berbagai alternatif usaha yang potensial meningkatkan pendapatan. Petani bisa memanfaatkan pinjaman untuk mengoptimalkan tanah. Di 
samping itu, pendampingan membuat masyarakat akan menjadi lebih optimis dalam pemanfaatan modal yang diperoleh.

2. Faktor adat dan budaya masyarakat yang beranggapan suatu hal yang bisa membuat malu saat menggadaikan (mengagunkan) barang, menggadaikan sesuatu hanya dilakukan pada kondisi-kondisi tertentu yang darurat bukan untuk meningkatkan taraf kehidupan.

3. Faktor kepercayaan kepada lembaga pemberi modal. Hal ini bisa diatasi dengan melibatkan perbankan syariah pada saat melakukan sosialisasi maupun pada tahap bina penerima sertifikat.

4. Pengalaman pribadi penerima sertifikat yang terlilit kredit macet sebelum ada kegiatan redistribusi tanah. Pengalaman ini menjadikan penerima sertifikat enggan mengakses modal dengan mengagunkan sertifikat tanahnya.

5. Pemahaman yang kurang tepat dari sebagian pihak perbankan di beberapa lokasi tentang catatan pada sertifikat tentang larangan pengalihan hak sertifikat redistribusi tanah selama 10 tahun. Pada tahap awal kondisi seperti ini diselesaikan dengan masyarakat atau pihak perbankan meminta penjelasan ke kantor pertanahan, tapi mulai tahun 2018 catatan pada sertifikat redistribusi tanah telah direvisi dengan dinyatakan secara eksplisit peralihan hak sebagai dampak dari mengagunkan sertifikat diizinkan.

\section{KESIMPULAN}

Kajian redistribusi tanah di Kabupaten Pasaman Barat sudah berlangsung sejak tahun 2009 hingga tahun 2018 dengan proporsi jumlah sertifikat yang sudah diagunkan sebesar kurang lebih 7\%. Hasil analisis regresi logistik menunjukkan bahwa luas tanah yang dimiliki serta tingkat kesejahteraan yang dinilai dari besaran pengeluaran merupakan faktor yang dapat meningkatkan peluang mengagunkan sertifikat tanah untuk mengakses modal. Sebaliknya jumlah anggota keluarga berperan menurunkan peluang tersebut.
Berbagai alasan terkait keengganan penerima redistribusi tanah untuk mengakses modal antara lain tidak adanya rencana penggunaan modal yang berkaitan dengan masih rendahnya pemahaman pemanfaatan modal, adat istiadat yang menilai mengagunkan barang sebagai hal tabu, kekurang percayaan kepada lembaga pemberi modal, pengalaman pribadi terlilit kredit macet serta pemahaman kurang tepat pihak perbankan tentang status pemilikan tanah.

Kajian lebih lanjut tentang luasan ideal tanah yang diredistribusikan perlu dilakukan agar keefektifan program redistribusi tanah lebih baik. Di samping itu, dalam setiap pelaksanaan redistribusi tanah perlu dilanjutkan dengan pendampingan bekerja sama dengan beberapa instansi teknis agar pemanfaatan sertifikat redistribusi tanah untuk mengakses modal dapat lebih optimal dan target peningkatan kesejahteraan penerima tanah redistribusi bisa tercapai.

\section{DAFTAR PUSTAKA}

Arisaputra, M. I. (2016). Acces Reform dalam kerangka reforma agraria dalam mewujudkan keadilan sosial. Jurnal Perspektif, 21(2), 8396.

Das, M. M. (2008). Agrarian reform: Lessons from the Philippines. Economic and Political Weekly, 43(26-27), 32-34.

Fagerland, M. W. \& Hosmer, D. W. (2012). A generalized Hosmer-Lemeshow goodness-offit test for multinomial logistic regression model. The Stata Journal, 12(3), 447-453.

Fatimah. (2015). Reforma agrarian dalam konteks peningkatan akses kaum tani miskin terhadap penguasaan tanah di Indonesia. Jurnal Hukum: Samudra Keadilan, 10(2), 191-203.

Isnaeni, D. (2017a). Kebijakan landreform sebagai penerapan politik pembaharuan hukum agraria yang berparadigma pancasila. $J U$-ke (Jurnal Ketahanan Pangan), 1(2), 83-97.

Isnaeni, D. (2017b). Kebijakan program redistribusi. Masalah - Masalah Hukum, 46(4), 308-317. 
Jubaya, S. \& Wulandari, E. (2020). Peran ruah pembiayaan pertanian KSM jaya amanah dalam mengimplementasikan inklusi keuangan petani. Jurnal Pemikiran Masyarakat Ilmiah Berwawasan Agribisnis, 6(1), 190-200.

Khaeri, H. \& Pawitan, G. (2018). Penerapan model regresi logistik biner pada motif faktor kewirausahaan perempuan. Prima: Jurnal PendidikanMatematika, 2(1), 67. doi:10.31000/prima.v2i1.428.

Mendola, M. \& Simtowe, F. (2015). The welfare impact of land redistribution: evidence from quasi-experimental initiative in Malawi. World Development, 72, 53-69.

Mukarati, J., Mongale, I. P., \& Makombe, G. (2020). Land redistribution and the South African economy. Agricultural Economic- Czech, 66(1), 46-54.

Nurohman, Y. A., Qurniawati, R. S., \& Hasyim, F. (2019). Dana desa dalam peningkatan kesejahteraan masyarakat pada Desa wisata menggoro. Jurnal Magisma, 7(1), 35-43. doi:10.35829/magisma.v7i1.38.

Purnamasari, L. \& Hutagalung, S. S. (2012). Reformasi agraria nasional (studi kasus program redistribusi tanah di Kecamatan Tanjung Bintang Kabupaten Lampung Selatan Tahun 2010 - 2011). J. Ilm. Adm. Publik dan Pembang, 3 (2), 554-569.

Redi, A., Prianto, Y., Sitabuana, T. H., \& Adhari, A. (2017). Konstitusionalitas hak masyarakat hukum adat atas hak ulayat rumpon di provinsi lampung. Jurnal Konstitusi, 14(3), 463. https://doi.org/10.31078/jk1431

Rianto, N. (2011). Indikator perubahan kesejahteraan masyarakat pasca pembebasan lahan untuk pembangunan infrastruktur pekerjaan umum dan permukiman. Sosek Pekerj. Umum, 3 (26), 183-192.

Sartika, S. R. \& Karyani, T. (2018). Studi Kasus: aksesbilitas petani kopi terhadap kredit dari lembaga keuangan bank. Jurnal Agro IndustriPerkebunan, 6(2),

87. doi:10.25181/jaip.v6i2.954.

Soetarto, E., Sihaloho, M., \& Purwandari, H. (2007). Land Reform by Leverage: kasus redistribusi lahan di Jawa Timur. Sodality Jurnal Sosiol. Pedesaan, 1(2), 271-282. doi:10.22500/ sodality.v1i2.5926.
Sugiyanto, Siregar, H., \& Soetarto, E. (2008). Analisis dampak pendaftaran tanah sistematik terhadap kondisi sosial ekonomi masyarakat di Kota Depok. Jurnal Manajemen dan Agribisnis, 5(2), 64-72.

Supanggih, D. \& Widodo, S. (2013). Aksesibitas petani terhadap lembaga keuangan (Studi kasus pada petani di desa Sidodadi kecamatan Sukosewu Kabupaten Bojonegoro). Jurnal Agriekonomika, 2(2),163-173.

Waryanta. (2016). Reforma Agraria: Momentum mewujudkan kemandirian ekonomi masyarakat kecil dalam mendukung ketahanan pangan. BHUMI: Jurnal Agraria danPertanahan, 2(2), 179. doi:10.31292/jb.v2i2.6.

Wati, D. R. (2015). Akses kredit mikro pada petani padi organik di Kabupaten Bogor. Agribusiness Journal, 9(2), 97110. doi:10.15408/aj.v9i2.5286.

Wati, D. R., Nuryartono, N., \& Anggraeni, L. (2018). Akses dan dampak kredit mikro terhadap produksi padi organik di Kabupaten Bogor. Jurnal Ekonomi Dan Kebijakan Pembangunan, 3(2), 7594. doi:10.29244/jekp.3.2.75-94.

Wiradi, G. (2000). Reforma Agraria: Perjalanan Yang Belum Berakhir. Bogor: Sajogyo Institute,Akatiga,KPA.

Zantsi, S. (2019). Profiling potential land redistribution beneficiaries in South Africa: implications for agricultural extension and policy design. South Africa Journal of Agricultural Extension, 47(4), 135-141. 